\title{
FGFR2 NP_000132.3:p.N549H
}

National Cancer Institute

\section{Source}

National Cancer Institute. FGFR2 NP 000132.3:p.N549H. NCI Thesaurus. Code C107604.

A change in the amino acid residue at position 549 in the fibroblast growth factor receptor 2 protein where asparag ine has been replaced by histidine. 